\title{
12. Concluding thoughts: new philanthropy, age-old problems
}

\author{
Natasha Y. Ridge
}

As Northern philanthropic foundations, particularly those from North America, have extended their reach and activities into the Global South, it is clear that many of the problems that have historically plagued the development sector are now being encountered by the philanthropic sector. The chapters in this volume reveal that philanthropic organisations working in education globally are facing a variety of similar challenges, including a North-South divide, issues related to collaboration, the growing influence of the private sector and a need for greater transparency. In the following sections, I will discuss each of these areas in turn before concluding with some thoughts on where future research on global trends in philanthropy and education might go next.

\section{THE NORTH-SOUTH DIVIDE}

The divide between the Global North and the Global South is discussed, either directly or indirectly, in the majority of chapters in this volume. These chapters echo earlier critiques of the aid sector, including those of Easterly (2006) and Samoff (2007), concerning aid regimes, soft power and the imposition by Northern donors of their ways of doing and thinking on Southern recipients. In this volume, several authors have discussed the unequal relationship between Northern donors and Southern recipients, including the ways in which Northern philanthropic institutions intentionally and unintentionally impose their cultures, values and/or practices on Southern recipients and partners.

Jaumont and Moja in their chapter exploring the Partnership for Higher Education in Africa (PHEA) (Chapter 7), are highly critical of use of the word 'partnership' to describe the relationship between the Northern foundations and their Southern counterparts that were members of the Partnership. They highlight the one-sided nature of the relationship and the ways in which the cultures and values of Northern entities were 
imposed on Southern partners, either directly or indirectly. They describe the inherent rigidity and the particular internal culture and values that Northern philanthropic foundations, particularly the older, more established ones, brought with them. Without understanding or being able to articulate differing values and cultural norms between the United States and African countries, Jaumont and Moja report that African universities felt that they were not equal partners in the PHEA. Rather than being able to articulate their own needs and requirements, they felt that they were mere recipients of whatever programme the Northern foundations felt was right for them. Drezner raises similar issues in his chapter on higher education (Chapter 6). Building on work by Steiner-Khamsi (2004), he describes how fundraising policies are borrowed and lent, including by U.S. foundations to African universities, and raises questions related to how culturally applicable they are.

Similar concerns regarding the disproportionate influence of Northern organisations on Southern partners are also expressed by Santos (Chapter 9). In his examination of the Intel Corporation and its support of Brazil's science fairs, Santos reveals how an outside entity attempted to shape an entire country's science curriculum. When Intel decided to discontinue its support of science fairs, presumably without any discussion with Southern partners such as Brazil, the direction and focus of science education in the country was directly impacted.

Taking a slightly different perspective in their account of the International Education Funders Group (IEFG), an umbrella organisation of philanthropic actors working in education, Haggerty, Magrath and Kelava describe what they call 'colonial influences of the flow of grant-making' (Chapter 3, p.45). They find that Anglophone foundations tended to focus on Anglophone countries while Francophone countries focused on Francophone countries, a finding similar to that of Jaumont and Moja. This linkage between philanthropic funding and former colonies raises many questions about not only the perpetuation of colonial spheres of influence but also of unequal partnerships, to use the words of Jaumont and Moja.

Bird and León's chapter on Peru (Chapter 8) takes a different approach but is still illuminating with regard to the negative impact of Northern institutions on philanthropy and education in the Global South. The authors discuss the impact of Northern multilateral donors, in this case the World Bank, on Southern economies and the effect of this on the local education sector and local philanthropy. In the case of Peru, the reclassifying of the country as an upper middle-income country meant that there was a sharp decrease in aid flows and a subsequent reduction in government funding for education. This, in turn, placed great pressure on 
local philanthropic actors to step in to fill the gaps. However, the less wellresourced, local philanthropic sector has been unable to meet the shortfalls in funding, and thus, the local education sector continues to face serious funding challenges.

While Ziswiler and Terway (Chapter 4) do not speak directly about the North-South divide, their chapter highlights the use of Northern financial instruments to achieve results in a Southern context. While the projects so far have been successful, little is said about the cultural appropriateness of such instruments or about the inherent values that accompany them. In research on microfinance, Bateman (2012) and Roy (2010) found that the microfinance movement often imposed Northern ways of banking on communities in the Global South, which did not always connect with local ways of transacting. As a result, these interventions did not provide sustainable benefits to the communities. In terms of innovative finance models, such as development impact bonds and the like, there may be similar inherent risks associated with the use of these instruments in the Global South by Northern philanthropic actors, something that should be considered moving forward.

The divide between the North and South and the continuation of unequal relationships by the philanthropic sector raises questions about whether Northern philanthropic organisations are actually empowering their Southern partners or perpetuating the principal-agent problem that has historically plagued the development sector. ${ }^{1}$

\section{INCREASING COLLABORATION}

The second challenge facing global philanthropy, which appears in several of the chapters, centres around the issue of collaboration. The growing awareness of the need for collaboration across various stakeholders is discussed by several authors. However, the chapters also reveal a lack of collaboration between the philanthropic and academic sectors.

In terms of seeking to foster greater collaboration between actors, Ziswiler and Terway touch upon this in their chapter (Chapter 4). The social finance models they discuss are contingent on working relationships between investors, philanthropic organisations and the implementer. They argue that these models are also pushing for greater collaboration between the private capital market and social development organisations and, thus,

\footnotetext{
1 In development aid, there are many complex principal-agent relationships that impact almost all aspects of aid delivery. For more information, see Martens, Mummert, Murrell and Seabright (2002) and Radelet (2006).
} 
have an important role to play in bringing stakeholders together around a particular project.

Similarly, in her chapter examining the growing role of corporations in education in Nigeria, Udo-Umoren (Chapter 10) explains that while companies in the past tended to give their corporate social responsibility (CSR) funds to non-profit organisations or charities, there is now a growing trend for them to partner with a wider range of actors. Specifically, she mentions the growing number of corporations working with governments and multilateral agencies on social issues such as education. However, she makes the point that the motivation behind this may also be related to helping corporations promote their business interests and influence policy-making.

Also connected to collaboration with governments, both our own chapter (Chapter 5) and the chapter by Matovich and Cardini (Chapter 11) highlight the benefits for philanthropic organisations that work closely with local and federal governments as well as the pitfalls of not being connected to them. In our chapter, we discuss how philanthropic organisations who were the most active in the public education sector spoke about having close connections and ties with government officials and/or ministers of education. The higher the level of collaboration, it seems, the easier it was for entities to be able to run programmes and influence education policy. From a slightly different perspective, Matovich and Cardini also speak at length about the role that collaboration between members of the government and the leadership of the Varkey Foundation played in terms of facilitating entry into the education sector for the Foundation in Argentina.

With regard to foundations collaborating with each other, Jaumont and Moja describe the joining of forces of U.S. foundations in the PHEA. Through coming together, not only did these foundations wield significantly more financial influence, but they also leveraged all their separate networks in order to gain access and exert influence both at the institutional and national levels. The chapter by Haggerty et al. also discusses at length the benefits of foundations collaborating and connecting through the IEFG as well as some of the challenges associated with facilitating such relationships.

In terms of the collaboration (or lack thereof) between philanthropic foundations and academia, several chapters speak to this point directly or indirectly. Two interlinked key trends emerge from this volume. First, it is clear that foundations are unlikely to carry out their own research or even fund research. Second, their work in the education sector that is done unilaterally, without the involvement of researchers, can at times place them at odds with the national or international academic community.

In terms of conducting and funding research, our chapter exploring philanthropy in education in the Middle East finds that only 11 per cent of 
foundations in the region conduct or fund education-related research. The low value placed on research and a lack of engagement with researchers on the part of philanthropic organisations in the Middle East unfortunately can mean that many philanthropic organisations pay little attention to current or past research that has already looked at many of the challenges they are seeking to address. In doing so, they run the risk of repeating the same mistakes or wasting scarce resources on programmes that have already proven to be ineffective.

An absence of engagement with academia appears to be a common factor across many of the descriptions of the activities and networks of foundations. Haggerty et al. explain how the IEFG addresses gaps 'in the field of global education philanthropy: a lack of opportunity for grant-makers to share information, collaborate or co-fund; and a perceived "information overload" that makes it difficult for foundations to stay on top of the latest research and innovations' (Chapter 3, p. 47). While the organisation provides linkages between the IEFG's members, new connections are not geared towards including academics, unless they are also employed at a grant-making organisation. As a result of the lack of connection between academia and philanthropic organisations, it may appear that academics are overly critical and unsupportive of the work of philanthropic organisations. However, perhaps with better engagement and collaboration between the two worlds, this would not be the case.

\section{GROWING INFLUENCE OF THE PRIVATE SECTOR}

As the number and influence of private philanthropic foundations increase in the education sector globally, there are renewed concerns about the influence of the private sector on public education, and, in particular, on the formal and informal networks that enable this (Davies, 2011; Reckhow \& Snyder, 2014; Ridge \& Kippels, 2019). Ball (2008, 2012, 2016) discusses the importance of these networks in much of his work on philanthropy, and we can see networks at play in many of the chapters in this volume, whether explicitly as in the cases of Brazil and Argentina or implicitly through the awarding of contracts and partnerships in the case of the UBS Optimus Foundation. For many private foundations, new or old, the cultivation of networks has been an essential part of their corporate background, and that these practices persist into their philanthropic work should probably not surprise us.

The importance of personal and corporate networks is well-described in the case of the Varkey Foundation's entry to Argentina. Matovich and Cardini describe how 'policies flow through networks at the same time 
that they are adapted to them... movements and adaptations involve different actors coming from diverse areas and with different interests and influences, assembling a discourse that is permanently legitimated by the network itself' (Chapter 11, p. 193). A well-developed relationship and support for particular politicians and their network resulted in favourable conditions for the Varkey Foundation to launch teacher training programmes across the country. Likewise, in Brazil, Santos explains how great care was taken by Intel to connect with government officials and non-profit leaders to gain support for the science fairs as well as to ultimately influence the national science curriculum.

It is these networks that enable the CEOs of private foundations to meet with ministers of education, gain access to closed-door meetings and have the right conversations with the right people. However, such networks may also enable them to avoid transparency about finances, connections and motivations. Without these networks, the majority of the work that private philanthropy does in the public education sector would probably not have happened in the way that it has, particularly if the philanthropic organisation originated outside of the country or region.

\section{THE NEED FOR GREATER TRANSPARENCY}

Finally, many chapters also discuss issues surrounding transparency, which again echo critiques by scholars of the foreign aid sector (Frumkin, 2006; Tyler, 2013). In the absence of a well-established legislative environment governing philanthropic organisations in many countries in the Global South, there is a lack of transparency surrounding both finances between philanthropic entities and recipients and to philanthropic entities from corporations or other sources (Cruz, 2011).

Key to the success and sustainability of philanthropic work in education is that organisations are perceived as trustworthy. Key to trust is transparency about activities and about finances. Haggerty et al. write about the value of building communities of trust and the barriers to this. In our own research on the Middle East, we also encountered issues related to this. In our case, it was difficult to gather information related to the budgets of foundations, beyond sweeping public relations statements about overall commitments. The majority of foundations working in education did not provide audited financial information on their websites. A key reason for this is the lack of clear, legal frameworks for philanthropic organisations in the region.

A lack of transparency about financial resources and their origins also may lead to incorrect assumptions about the independence and type of 
philanthropic organisations. Srivastava and Read (Chapter 2) discuss how they faced challenges relating to a lack of information about organisations' financial assets and flows when attempting to categorise organisations, which often led them to make best guesses as to an organisation's status.

The need for financial transparency is also indirectly highlighted by Ziswiler and Terway. In their chapter discussing the use of social finance, one party pays for the development impact bond intervention while another implements it. An investor, such as UBS Optimus Foundation, pays for the initial costs, and then if the parameters of success are reached, they receive a payout by another separate entity, such as the government. In such complex financial transactions and flows, it is imperative not only that governments are aware of where the money is flowing from and to but also who the various partners and recipients are. The many layers between donor and recipient may be a potential source of confusion, and perhaps mistrust, when trying to ensure sustainability in the long term.

Bird and León, in their discussion of philanthropic organisations in Peru, find a linkage between greater financial transparency and good governance in social investment organisations. In Peru, social organisations whose board compositions changed every 2.6 years versus every 5.1 were more likely to have published financial information, one form of greater transparency. Bird and León make a call for more transparency in the sector in order to ensure that initiatives are doing what is most needed to assist the education sector.

Finally, Udo-Umoren in her examination of CSR in Nigeria, also looks at issues surrounding financial transparency. She explains that when it comes to CSR, it is difficult to determine exactly how much companies actually spend and how much, in particular, on education. For governments, there is a need to be able to quantify the amounts that are being spent on education and where so that financial resources can be most effectively used and to determine if there are other motivations behind the spending. However, a lack of transparency in the sector can hinder this. Overall, the majority of chapters highlight a lack of transparency, particularly related to financial transparency, as a key challenge to the success of the global philanthropic sector.

\section{FUTURE RESEARCH AND CONCLUDING THOUGHTS}

Moving forward, it is clear that there are many opportunities for philanthropic organisations working in the global education sector to make positive contributions. There is also a great deal of positivity surrounding the entry 
of such organisations into the development sector on the part of Southern governments. As many have grown weary of the conditionality attached to official development assistance (ODA), governments may consider relationships with philanthropic entities to be a liberating exchange (Grady, 2014; Moyo, 2009). However, while there may be no explicit conditionality attached to philanthropic contributions, governments need to be careful that they are not exchanging one regime for another (Ball, 2008; Giridharadas, 2018; Kramer, 2018). A lack of research and regulations means that recipient governments may not have all the information they need to make informed decisions about working with philanthropic donors. In addition, should things not work out, they may find themselves without any recourse.

In the case of bilateral assistance, democratic donor countries are accountable to their electorates and to various oversight committees. However, the question of who philanthropic organisations are accountable to is far less clear. In fact, this has been one of the biggest criticisms of philanthropic organisations in their domestic settings (Frumkin, 2006; Green, 2013). In our volume, the question of accountability lurks at the back of many of the chapters, the elephant in the room if you will. As Reckhow and Tompkins-Stange (2018) describe, philanthropic organisations can give and take funds away as quickly or slowly as they like, whenever and from wherever they choose. In Santos's chapter, it appears that Intel gave little thought to how its quick 'pivot' away from science fairs might negatively impact science education across the country. The fast-moving change of priorities and rapid pullback of funds by philanthropic organisations have also been well documented in the United States by Tompkins-Stange (2018), who looked at the case of the Gates Foundation, its rapid support of small schools and its subsequent, equally rapid rollback.

It is clear that the chapters in this volume raise many more questions than they answer regarding global trends in philanthropy and education. The rapid expansion of philanthropic activity in the global education sector is a recent phenomenon and, as such, is still relatively unstudied. Even in the United States, which has a far longer history of philanthropic involvement in education, there is too little scholarship examining the impact of private philanthropy on public goods. However, in other parts of the world, there is even less. Much of the existing research is, as we described, hindered by weak or non-existent regulatory requirements of philanthropic entities, in particular surrounding transparency of finances. Future research examining the legal and regulatory environments in which philanthropic organisations operate across and within countries in the Global South would make a valuable contribution to the field, especially with so many large Northern philanthropic organisations seeking to work further afield. 
In addition to understanding the context in which philanthropy operates, there is also a need for further methodological and theoretical research of the sector. Srivastava and Read demonstrate the complexity of the field and the need for the construction of typologies through which to understand different types of actors. Theoretical frameworks need to be developed that can account for the messiness of the field, its indirect impact on policy-making and its blurring of corporate and philanthropic interests and of for-profit and not-for profit streams in single entities. While it would be impossible and perhaps undesirable to have anything definitive, there is, in our experience, a real need at the most basic level to be able to distinguish between financially independent philanthropic organisations and those that are not. Our research in the Middle East revealed that many organisations that identified as philanthropic organisations were in fact middlemen, taking grants from larger foundations or governments and then passing them on to non-profits and other organisations. Thus, estimates about the size of philanthropic activity is likely to be overstated given that money is often just being recirculated and double- or triple-counted.

Finally, but not exhaustively, there is the need for more research examining the networks through which these new actors are operating. In his recent chapter in Parreira do Amaral, Steiner-Khamsi and Thompson (2019), Ball (2019) examines the case of the Michael and Susan Dell Foundation in India and the complex network of actors surrounding its work. This kind of research, which both Matovich and Cardini and UdoUmoren also utilise, is valuable in terms of understanding not only why policies and partnerships are formed and shaped but also how. There are numerous closed-door meetings of philanthropic actors happening every year, and these gatherings not only connect them with each other but also with governments and the private sector. However, notably absent from many of these meetings are academics. Thus, further study of networks connecting private foundations with government officials, corporations, the non-profit sector and academia will be crucial to understanding how foundations are operating in a post-aid world.

New philanthropic actors move with far greater speed than their predecessors or than academia. They are also increasingly more focused on delivering measurable results and on scalability, in line with the business backgrounds that many have (Brest, 2012). However, often missing from their activities seems to be self-reflection and a lack of research into what has been tried before and whether or not it was successful. By engaging and collaborating with academics, philanthropic organisations would benefit in that their initiatives could be more robust and built on what has gone before and, as a result, more successful. For academics, there is a need 
also to move beyond simplistic and theoretical explanations of the motivations of foundations and to instead examine exactly what is being done, by whom and how. While there is a need for healthy scepticism, there is also a need for engagement and a move away from cynicism in order to prevent open-minded philanthropists and philanthropic entities from becoming completely disconnected from academia.

Moving forward, we hope that there will be increasingly more research on philanthropy and education that brings practitioners, philanthropic leaders and academics together as we have attempted to do in this volume. Through greater collaboration and more rigorous research, not only will philanthropic organisations be able to ground their work in evidence but academics will be able to make a tangible contribution to achieving Sustainable Development Goal 4 and numerous other national and regional educational aspirations in the most ethical, efficient and effective way possible.

\section{REFERENCES}

Ball, S. J. (2008). New philanthropy, new networks and new governance in education. Political Studies, 56(4), 747-765.

Ball, S. J. (2012). Global education Inc.: New policy networks and the neo-liberal imaginary. London, UK: Routledge.

Ball, S. J. (2016). Following policy: Networks, network ethnography and education policy mobilities. Journal of Education Policy, 31(5), 549-566.

Ball, S. J. (2019). Serial entrepreneurs, angel investors, and capex light edu-business start-ups in India: Philanthropy, impact investing, and systemic educational change. In M. Parreira do Amaral, G. Steiner-Khamsi, \& C. Thompson (Eds.), Researching the global education industry: commodification, the market and business involvement (pp. 87-113). Cham, Switzerland: Palgrave Macmillan.

Bateman, M. (2012). The role of microfinance in contemporary rural development finance policy and practice: imposing neoliberalism as 'best practice'. Journal of Agrarian Change, 12(4), 587-600.

Brest, P. (2012). A decade of outcome-oriented philanthropy. Stanford Social Innovation Review. Retrieved January 5, 2019, from https://ssir.org/articles/entry /a_decade_of_outcome_oriented_philanthropy\#

Cruz, A. (2011). Tracking global philanthropy and remittances. Devex, 21 November. Retrieved January 20, 2019, from https://www.devex.com/news/ tracking-global-philanthropy-and-remittances-76690

Davies, P. (2011). The role of the private sector in the context of aid effectiveness. Paris, France: Organisation for Economic Co-operation and Development.

Easterly, W. R. (2006). The white man's burden: why the West's efforts to aid the rest have done so much ill and so little good. London, UK: Penguin Books.

Frumkin, P. (2006). Accountability and legitimacy in American foundation philanthropy. In K. Prewitt, M. Dogan, S. Heydemann, \& S. Toepler (Eds.), The legitimacy of philanthropic foundations: United States and European perspectives (pp. 99-122). New York, NY: Russell Sage Foundation. 
Giridharadas, A. (2018). Winners take all: The elite charade of changing the world. New York, NY: Knopf.

Grady, H. (2014). Philanthropy as an emerging contributor to development cooperation. New York, NY: UNDP.

Green, M. (2013). Philanthropy and official development assistance: A clash of civilisations?. Paris, France: OECD Development Centre. Retrieved January 5, 2019, from https://www.oecd.org/site/netfwd/Philanthropy $\% 20$ and $\% 20$ Official $\% 20$ Deve lopment $\% 20$ Assistance $\% 20 \mathrm{~A} \% 20$ Clash $\% 20$ of $\% 20$ Civilisations.pdf

Kramer, M. (2018). Are the elite hijacking social change? Stanford Social Innovation Review. Retrieved January 20, 2019, from https://ssir.org/book_reviews/entry/ are_the_elite_hijacking_social_change

Martens, B., Mummert, U., Murrell, P., \& Seabright, P. (2002). The institutional economics of foreign aid. Cambridge, UK: Cambridge University Press.

Moyo, D. (2009). Dead aid: Why aid is not working and how there is a better way for Africa. New York, NY: Farrar, Straus and Giroux.

Parreira do Amaral, M. P, Steiner-Khamsi, G., \& Thompson, C. (2019). Researching the global education industry: commodification, the market and business involvement. Cham, Switzerland: Palgrave Macmillan.

Radelet, S. (2006). A primer on foreign aid. Washington, DC: Center for Global Development. Retrieved January 5, 2019, from https://papers.ssrn.com/sol3/ Data_Integrity_Notice.cfm?abid=983122

Reckhow, S., \& Snyder, J. W. (2014). The expanding role of philanthropy in education politics. Educational Researcher, 43(4), 186-195.

Reckhow, S., \& Tompkins-Stange, M. (2018). Financing the education policy discourse: philanthropic funders as entrepreneurs in policy networks. Interest Groups \& Advocacy, 7(3), 258-288.

Ridge, N., \& Kippels, S. (2019). UNESCO, education and the private sector: A relationship on whose terms? In M. Parreira do Amaral, G. Steiner-Khamsi, \& C. Thompson (Eds.), Researching the global education industry: commodification, the market and business involvement (pp. 87-113). Cham, Switzerland: Palgrave Macmillan.

Roy, A. (2010). Poverty capital: Microfinance and the making of development (3rd ed.). New York, NY: Routledge. https://doi.org/10.4324/9780203854716

Samoff, J. (2007). Education quality: The disabilities of aid. International Review of Education, 53(5-6), 485-507.

Steiner-Khamsi, G. (Ed.). (2004). The global politics of educational borrowing and lending. New York, NY: Teachers College Press.

Tompkins-Stange, M. (2018). Too big to fail: 'Big Bet' philanthropy and constructive failure at the Gates Foundation. In J. P. Greene \& M. Q. McShane (Eds.), Failure up close: what happens, why it happens, and what we can learn from it (pp. 123-132). Lanham, MD: Rowman \& Littlefield.

Tyler, J. (2013). Transparency in philanthropy: An analysis of accountability, fallacy, and volunteerism. Washington, DC: The Philanthropy Roundtable. Retrieved January 20, 2019, from https://www.philanthropyroundtable.org/file_uploads/ transparency_in_philanthropy.pdf 